\title{
International shocks and growth in emerging markets
}

\author{
G. Ganguly and S. Poshakwale* \\ Centre for Research in Economics and Finance \\ Cranfield School of Management \\ Cranfield University \\ Bedfordshire, MK43 0AL \\ Tel: +44 (0)1234 754404 \\ Email: sunil.poshakwale@cranfield.ac.uk \\ gaurav.ganguly@hotmail.com
}

https://doi.org/10.1016/j.gfj.2015.01.003

International shocks and growth in emerging markets 


\begin{abstract}
The paper provides evidence on the extent and channels of transmission of international shocks on the economic growth of emerging markets. Using a block dynamic factor model, the shocks are decomposed into four components; a general global component, an activity based component, a financial component and a commodity price component. Using a sample of 75 emerging markets over the period 1992-2009, the paper finds that the average effect of international shocks on emerging markets' growth over the entire sample period is negligible, which supports the classic view of isolated, de-coupled emerging markets. However, there is considerable variation both over time, over cross-section and across factors. When we split our sample by time period, we find greater effect of the international factors on the emerging markets' growth during 2002-2009. There is evidence which suggests that sensitivity to international shocks has increased over time and at the country level these sensitivities are more pronounced. Although the drivers of integration vary as does the sensitivity to alternative sources of shocks, we find that certain emerging markets have become considerably more integrated with the global economy than others. Overall, there is evidence of a significant impact on the economic growth of some emerging markets of the international shock caused by the global financial crisis.
\end{abstract}

JEL Classification: F2, G1

Keywords: Economic growth, emerging markets, factor models, GDP growth, globalisation. 


\section{International shocks and growth in emerging markets}

\section{Introduction}

An important issue for academic research, investors and policy makers is the extent to which growth in emerging markets is affected by negative external shocks. This is particularly relevant as with increasing international flows of capital, goods and services, emerging markets become not only further integrated with the global economy but also have greater relevance for global growth. ${ }^{1}$ While such integration leads to benefits through access to international markets and capital, there may also be undesirable effects stemming from greater susceptibility to the business cycle and financial markets related shocks from advanced economies. This is particularly relevant to consider in view of the global financial crisis following the US subprime crisis of 2007-2008 to which emerging markets, at least based on expert evidence at the time, showed increased vulnerability leading to renewed concerns about the benefits of global integration. ${ }^{2}$ For policy makers, understanding the size and nature of global contagion aids design of appropriate policy. International spill-overs may have serious consequences for emerging markets that do not have the luxury of protective mechanisms such as 'automatic stabilisers' and where the transmission mechanism of monetary policy may work even less effectively than it does in developed markets. In such circumstances economic rates of growth may decline, the impact may be long lasting and the effect on poorer segments of society may be quite large. For international investors, increased transmission of international shocks would mean reduced diversification benefits which might increase reluctance to invest in such countries and/or may increase the chances of capital flight. This risk aversion may in turn, exacerbate the sensitivity of emerging markets to global shocks.

This paper examines several topical issues. Firstly, we re-visit the issue of emerging markets and their sensitivity to global shocks. Although there is large literature, it is divided on this subject and we consider it worth re-visiting to clarify issues of linkages and impact across a wide cross section of emerging markets and over a period of increasing globalisation. Secondly, the response of emerging markets to the extreme global shock from advanced economies in 2007-2008 is an "extreme event" in modern economic history that deserves further attention. Idiosyncratic growth dynamics may drive emerging markets growth for a range of

\footnotetext{
${ }^{1}$ See Economist, July $21^{\text {st }} 2012$.

${ }^{2}$ The IMF April 2009 World Economic Outlook reported a contraction in emerging economy GDP growth of 4 percent in the fourth quarter of 2008. The WTO noted that falls in trade, financial flows and commodity prices had all affected emerging markets and that no region of the world had been left untouched.
} 
advanced economies shocks but this may not hold for an extreme shock. Average estimates of co-movement therefore fail to capture the time varying nature of the true responsiveness. Thirdly, as the grouping of emerging markets is far from homogenous, it is worth considering the distribution of sensitivity across countries. Finally, we study the responsiveness of emerging markets to alternative international factors of relevance, making a clear separation between activity shocks and those emanating from financial movements or from changes in commodity prices.

We start with a summary of the literature on linkages between emerging markets and the global economy. Changes in policy, technology and in politics have led to a dramatic increase in the importance of emerging markets for global growth over the last two decades. While there is little dispute that this has been accompanied by increased flows of trade, capital and services (the more visible side of globalisation), there is less consensus on the impact this has had on output fluctuations in emerging economies. One strand of thought suggests that shocks in advanced economies are major drivers of emerging market growth. Rand and Tarp (2002) and Akin and Kose (2007) support the view that shocks to advanced economies are principal drivers of GDP growth in emerging markets. Similarly, Kouparitsas (2001) finds that up to $70 \%$ of consumption volatility in emerging markets is driven by economic shocks in advanced economies. Using high frequency data, Edwards (2010), examines the effect of changes in the US Federal Reserve's fund rate on interest rates of emerging markets. He also investigates the impact of shocks arising from changes in dollar-Euro exchange rate, oil prices, risk ratings and capital mobility. Edward's overall conclusion is that the impact of shocks differs across markets. For Latin American markets the impact is rapid but for Asian markets the impact is felt over a long period of time. Dooley and Hutchinson (2010) examine financial asset prices post the events in the US since autumn 2008 and find an increase in asset price correlations between the US and several emerging markets, while prior to this, such financial correlations were low.

However, this conclusion does not square well with a parallel strand that fails to find evidence of synchronous business cycles between the developed and emerging economies. Kose et al (2008) search for global, regional and country specific co-movement in a sample of 106 industrialised and emerging countries and conclude that while global co-movement can be observed over the period 1960-2005, the global factor has become less important during the latter part of the sample period (1985-2005). Kose et al (2008) point out that this analysis is not consistent with the hypothesis that increasing trade and financial integration leads to 
increased co-movement of business cycles. They suggest that country specific factors explain the majority of the variation in emerging market data. Chambet and Gibson (2008), examine the level of financial integration and conclude that to a large extent emerging markets are still segmented. They report that trade openness plays a key role and countries which are less open to trade are more segmented. Similar findings are reported by Dooley and Hutchinson (2009) who examine the transmission of shocks following the US subprime crisis. They find that emerging markets appeared to be somewhat insulated from the developments in the US economy from early 2007 to the middle of 2008 . However, emerging markets did react quite strongly to a number of news events in the period after the summer of 2008. The evidence supports their decoupling-recoupling hypothesis. Fidrmuc and Korhonen (2010) support the de-coupling hypothesis in that they find very little business cycle correlation between China and India and advanced economies over the period 1992-2007 ${ }^{3}$. In a recent study, Didier, Hevia and Schmukler (2012) find that though emerging economies could not shield themselves from the transmission of shocks arising from the global financial crisis of 2008-2009, they showed much more resilience during the crisis compared to the crises that occurred prior to the 2007 .

Another key issue is that the picture of advanced economies having a homogenous economic impulse that spills-over to emerging markets is too stylised. Studies that have focussed on spillovers from individual countries to the rest of the world also confirm the link between individual advanced economies and the emerging markets. Such research has tended to investigate spillovers from the US, in line with the over-used expression 'When the USA sneezes, the rest of the world catches a cold'. For instance Arora and Vamvakides (2001) find that a 1\% increase in US GDP increases GDP in the rest of the world by $1 \%$. Canova (2005) suggests that $50 \%$ of the business cycle in Latin America is driven by the US shocks (with 90\% of business cycle variation coming from industrialised countries). Such evidence suggests that emerging markets have a homogenous response to shocks from industrialised countries such as the US. We challenge this premise in the paper because emerging markets are heterogeneous and grouping them together is, to some extent, mis-leading. There is no prima facie reason to believe that emerging economies respond in the same way to international shocks. We expect a far fuzzier picture of international relationships to hold, rather than one where advanced economies and emerging markets are neatly boxed into homogenous groups

\footnotetext{
${ }^{3}$ They claim some increase in correlation during the course of 2008 but it is not possible to assess the robustness of this claim as they do not provide confidence intervals for their correlation calculations.
} 
Finally, despite extant research, it is still unclear whether countries are exposed to the global economy through a single channel or through multiple channels. It is critical to disentangle the international shocks to understand the channels through which spill-overs work. Akin and Kose (2007) put forward the trade angle. Similarly, Baxter and Kouparitsas (2004) advance the view that comovements in output depends on the extent of bilateral trade while Burstein et al (2008) suggests that production sharing can lead to co-movement in manufacturing output. In contrast, Bui et al (2010) argue that, in the context of the economic crisis that started in 2007, the financial markets related shocks have been important, particularly those from the US and the UK. These financial shocks help explain global movements in economic activity. More recently, Berkman, Gelos, Rennhack and Walsh (2012) investigate the channels of shock transmission to emerging economies and report that though financial factors played a major role in transmitting the impact of the global financial crisis, trade linkages also seem to have played a key role in transmission of shocks particularly for non-emerging market developing countries. The literature on coupling and decoupling often mixes up activity and financial shocks. We conjecture that activity spill-over from industrial economies to emerging markets may have increased over the last 10 years. However, when we have a large shock like the one in 2008, coupling does increase but not because emerging markets become more sensitive to the activity shock necessarily but rather they become more sensitive to the financial shock as has been shown in Berkman et al (2012).

A key contribution of our paper is that we distinguish different types of shocks and are able to demonstrate that emerging markets have become more sensitive to advanced economy activity shocks over time but the sensitivity is generally quite low and remain largely unchanged during the peak of the financial crisis in 2008. Consistent with Berkamn et al (2012) we too find that for some emerging markets, the sensitivity to the financial shocks increased during 2008.

The paper is different from the work done in this area so far in three significant ways. First while Didier et.al., (2012) investigate the impact of global financial crisis for a large number of countries grouped under advance, emerging, low-income economies and also based on geographic groupings (Asia, MENA, CIS and Latin America), in this study we not only provide evidence based on the commonly used geographic groupings but also show the impact on the economic growth of individual countries. Second, we also provide evidence based on alternative groupings based on the relative importance of countries in terms of Exports and Foreign Direct Investments (FDI). Third, we use a unique methodology that allows us to isolate 
the effects of economic activity, financial, commodity, and global factors in transmission of shocks and thereby provide evidence of their relative impact on the economic growth of emerging markets.

Using a sample of 75 diverse group of emerging markets spread across all geographic regions over the 17 year period 1992-2009, the paper employs a block dynamic factor model, to decompose shocks into four categories i.e., activity, financial, commodity and global. The results suggest that though the average effect of international shocks on emerging markets' growth over the entire sample period is negligible, which supports the classic view of isolated, de-coupled emerging markets, there is evidence that sensitivity to such shocks has increased over time and at the country level these sensitivities are more pronounced. Although the drivers of integration vary as does the sensitivity to alternative sources of shocks, some emerging markets have become considerably more integrated with the global economy. Overall, there is evidence of a significant impact on the economic growth of some emerging markets of the global financial crisis following the collapse of US sub-prime mortgage market in 2007-2008.

Rest of the paper is organised as follows. The next section discusses the methodology we employ to measure the impact of international shocks. Section 3, reports and explains the empirical results, and the final section concludes.

\section{Data \& Methodology}

\subsection{Data}

The paper uses a large sample of 75 emerging economies and covers a diverse group of emerging markets spread across all geographic regions. The data cover 17 year period starting from 1992 and ending in 2009. For measuring economic activity shocks in G5 economies we use GDP and imports data. Financial shocks in the G5 economies are measured by the changes stock prices using major stock market indices and the commodity shocks are measured by the changes in the international commodity prices. The dataset we use comprises 22 variables including quarterly GDP and imports, stock prices of G5 economies and 7 commodity price indices which include Agriculture and Materials, Beverage, Food, Industrial Materials, Metal, Non-fuels and Energy sector indices sourced from the IMF. G5 activity and stock prices are sourced from national statistics offices. The list of emerging markets and details of activity, financial and commodity variables used in the paper are given in Appendix A and Appendix B respectively. Additionally, to control for emerging market country specific internal policy and 
cyclical conditions, we use Trade/GDP ratio, the Investment/GDP ratio and the Quarterly Inflation rate as control variables which proxy price, trade and financial conditions respectively.

\subsection{Measuring international shocks.}

An integral part of this study is the measurement and categorisation of international shocks. While a variety of international shocks may affect emerging markets, we restrict attention to those that emanate from economic activity and place an emphasis on shocks from major economies. We use a parsimonious data set to measure shocks to G5 economic activity, specifically an activity shock given by GDP and imports, financial shocks measured by stock prices and, commodity shocks by changes in international commodity prices. We measure these through a factor model that imposes a block factor structure. We acknowledge the presence, possibly weak, of a common factor across these three sources which may lead to correlation between activity, financial and commodity prices. We therefore, in addition to these three shocks, also measure the common component across activity, financial and commodity price variables.

The block factor structure allows each variable in our dataset to be explained by an idiosyncratic component and two common components, namely a global factor and a block specific factor. For a specific variable $y_{i}$, using the block structure we write the variation in $y_{i}$ as:

$$
y_{i t}=\beta_{G i} F_{G, t}+\beta_{S, i} F_{S t}+\varepsilon_{i t}
$$

Where $y_{i t}$ represents variable ' $i$ ', at time period ' $t$ '. For each variable, there are two relevant international factors - a single world or global factor $F_{G t}$ that is common to all variables and a block specific factor $F_{s, t}$ that is specific to a block only. There are three such block factors one each for activity, financial and commodity price variables. The residual return, $\varepsilon_{i t}$ is multivariate normal, with zero mean, unit variation and zero correlation amongst off diagonal elements.

Given the block specific structure, all correlation across groups is captured by the global factor and within groups by both the global factor and the block specific factor. To see this, note that the co-variance between any two variables is given by:

$$
\operatorname{cov}\left(y_{m}, y_{n}\right)=\operatorname{cov}\left(\beta_{G m}^{\prime} F_{G}, \beta_{G n}^{\prime} F_{G}\right)+\operatorname{cov}\left(\beta_{S m}^{\prime} F_{S}, \beta_{S n}^{\prime} F_{S}\right)+\operatorname{cov}\left(\varepsilon_{m}, \varepsilon_{n}\right)
$$


for two variables ' $m$ ' and ' $n$ ' $(m \neq n)$ and block ' $S$ ' $=A, F$ and $C$ (activity, financial and commodity price respectively). Given the imposed orthogonal structure of the factors, there is no cross-covariance between the global and any of the block factors and the second term in (2) is non-zero only when variables ' $m$ ' and ' $n$ ' are in the same block. The factors capture major international forces of co-movement and we consider any remaining variation to be idiosyncratic.

To estimate the model in (1), we rely on a Gibbs sampling procedure using the Kalman filter and Bayesian regression. We start by writing (1) in matrix form:

$$
\left[\begin{array}{c}
y_{A 1, t} \\
y_{A 2, t} \\
\cdot \\
y_{A N, t} \\
y_{F 1, t} \\
\cdot \\
y_{F M, t} \\
y_{C 1, t} \\
\cdot \\
y_{C K, t}
\end{array}\right]=\left[\begin{array}{cccc}
\beta_{G, A 1} & \beta_{A 1} & 0 & 0 \\
\beta_{G, A 2} & \beta_{A 2} & 0 & 0 \\
\cdot & \cdot & \cdot & \cdot \\
\beta_{G, A n} & \beta_{A n} & 0 & 0 \\
\beta_{G, F 1} & 0 & \beta_{F 1} & 0 \\
\cdot & \cdot & \cdot & \cdot \\
\beta_{G, F n} & 0 & \beta_{F n} & 0 \\
\beta_{G, C 1} & 0 & 0 & \beta_{C 1} \\
\cdot & \cdot & \cdot & \cdot \\
\beta_{G, C n} & 0 & 0 & \beta_{C n}
\end{array}\right]\left[\begin{array}{c}
F_{G, t} \\
F_{A, t} \\
F_{F, t} \\
F_{C, t}
\end{array}\right]+\left[\begin{array}{c}
\varepsilon_{1 t} \\
\varepsilon_{2 t} \\
\cdot \\
\cdot \\
\varepsilon_{L, t}
\end{array}\right]
$$

where $L=N+M+K$. The factors themselves are given an $\mathrm{AR}(1)$ specification to account for any serial correlation in global events, such that:

$$
\left[\begin{array}{l}
F_{G, t} \\
F_{A, t} \\
F_{F, t} \\
F_{C, t}
\end{array}\right]=\left[\begin{array}{cccc}
\phi_{G} & 0 & 0 & 0 \\
0 & \phi_{A} & 0 & 0 \\
0 & 0 & \phi_{F} & 0 \\
0 & 0 & 0 & \phi_{C}
\end{array}\right]\left[\begin{array}{c}
F_{G, t-1} \\
F_{A, t-1} \\
F_{F, t-1} \\
F_{C, t-1}
\end{array}\right]+\left[\begin{array}{l}
\eta_{G t} \\
\eta_{A t} \\
\eta_{F t} \\
\eta_{C t}
\end{array}\right]
$$

Given a state space representation of (3) and (4) we can obtain estimates of the factors via the Kalman filter for appropriate starting values of parameters. The Kalman filter works by using prediction error decomposition to extract the unobservable factors. For unknown parameters, it is possible to solve for parameters using Maximum Likelihood but we prefer a Gibbs sampling approach which avoids the issues that arise when estimating high dimensional 
problems using the Kalman form of the likelihood function. Given random initial estimates of the loadings, we use the Kalman filter to obtain estimates of the state vector $F=\left(F_{G}, F_{A}, F_{F}, F_{C}\right)$ and then use the Kalman smoother to smooth our inference on estimates of the state vector at time ' $\mathrm{t}$ ' given the entire information set ' $T$ '. We first write the model in (3) and (4) in state space form:

$y_{t}=H \xi_{t}$

$\xi_{t}=A \xi_{t-1}+v_{t}$

Where

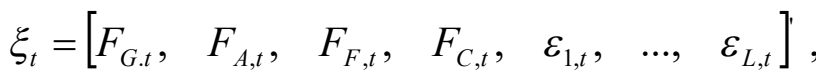

$H=\left[\begin{array}{cccccccccc}\beta_{G, A 1} & \beta_{A 1} & 0 & 0 & 1 & 0 & . . & . & \ldots & 0 \\ \beta_{G, A 2} & \beta_{A 2} & 0 & 0 & 0 & 1 & . . & . & \ldots & 0 \\ . & . & . & . & . & . & . . & . & \ldots & 0 \\ \beta_{G, F 1} & 0 & \beta_{F 1} & 0 & 0 & 0 & . . & 1 & \ldots & 0 \\ . & . & . & . & . & . & . . & . & . . & 0 \\ \beta_{G, C K} & 0 & 0 & \beta_{C K} & . & . & . . & . & . . & 1\end{array}\right]$,

$A=\left[\begin{array}{ccccccc}\phi_{G} & 0 & 0 & 0 & . & \ldots . & 0 \\ 0 & \phi_{A} & 0 & . & . & \ldots . & 0 \\ . & 0 & \phi_{F} & 0 & . & \ldots . & 0 \\ . & . & 0 & \phi_{C} & 0 & \ldots & . \\ . & . & . & . & . & \ldots . & . \\ . & . & . & . & . & \ldots & . \\ 0 & . & . & . & . & \ldots . & 0\end{array}\right]$ and

$v_{t}=\left[\begin{array}{llll}\eta_{G t} & \eta_{A t} & \eta_{F t} & \eta_{C t}\end{array}\right]$

We jointly estimate parameters and factors using the Carter and Kohn (1994) algorithm, and use a multi-move Gibbs sampling procedure to draw a single realisation of the state vectors from their joint distribution. These realisations are then employed in a Bayesian regression framework to estimate factor loadings. This allows us to take a draw from the joint distribution of the loadings, which serves as estimates for the next iteration of the Kalman filter. We 
perform this iteration 8000 times and use these iterations to obtain averaged values of loadings and factors.

As the standard factor representation requires $\mathrm{I}(0)$ variables, we first test all variables for stationarity using a standard ADF test. As we cannot reject the random walk hypothesis, we take first $\log$ differences of all variables. Additionally, to prevent individual variables from contributing unduly to the overall variation, all variables are standardised.

\subsection{Measuring the impact of international shocks on emerging markets}

The large literature on the determinants of growth in emerging markets has approached this from two directions. The first has addressed the question that Temple (1999) asks, namely, 'Why have some countries grown rich while others remained poor?' This arm of the literature has focussed on structural models of growth and has attempted to understand the long term determinants of a country's progress given its initial conditions. Balanced against this strand of the literature is an equally weighty arm that concentrates on finding the best short term determinants of growth, paying particular attention to decomposing GDP into long run vs short run trends. Borrowing from both enables a simple growth model that is specified as:

$\Delta y_{i t}=\sum_{j=1}^{J} \alpha_{j} \Delta y_{i t-j}+\sum_{k=1}^{K} \sum_{s=1}^{S} \beta_{s, k} \Delta x_{i k, t-s}+\sum_{p=1}^{P} \sum_{m=1}^{M} \theta_{p} f_{p, t-m}+u_{i t}$

where GDP growth, $\Delta y_{i t}$, for country ' $i$ ', $i=1, \ldots ., 75$, and for quarter ' $t$ ', is explained in a dynamic setting by incorporating ' $J$ ' lags of growth, ' $S$ ' lags of ' $K$ ' additional country specific explanatory variables, $\Delta x_{i t}$, and ' $M$ ' lags of ' $P$ ' variables, $f_{t}$, that summarise international shocks.

In addition to lagged GDP growth, emerging market specific variables in equation (6) reflect internal policy and cyclical positions. There is a large literature that experiments with alternative variables in such a specification and drawing from this literature, equation (6) includes the Trade/GDP ratio, the Investment/GDP ratio and the quarterly inflation rate ${ }^{4}$. While this is not an exhaustive set of domestic variables, it summarises important price, trade and financial conditions as well as key components of development policy. These variables

\footnotetext{
${ }^{4}$ Levine and Renelt (1992)
} 
enter in growth rate terms rather than in levels to remove the effects of persistence and to capture the effect that changes in policy have on growth. The inclusion of country specific control variables does not just reflect the need to control for endogeneity between growth and the control variables. Given that control variables proxy for policy changes, such variables may also reflect policy response to the international environment.

A technical detail of this specification is that it mixes frequencies. Growth and inflation are in quarterly terms while the investment and trade ratios appear as annual differences. A major reason for this is data driven, in that quarterly data on these two ratios are not widely available but the inclusion in annual terms also reflects the idea that these two variables reflect slow moving underlying structural change. When it comes to lag length specification in this model, 4 quarters for the lagged dependent variable for the inflation rate are used, while for the investment rate and the trade ratio only a lagged single year's difference is included. As annual data follow a calendar year, this means that equations for any quarter ' $t$ ' of a particular year will have the same value of the trade and investment ratio, namely the change between ' $Y-1$ ' and ' $Y-2$ ' where ' $Y$ ' represents the calendar year for the quarter represented by time period ' $t$ '. International effects are represented by the factors estimated in the previous section. All four factors from the international factor model are included, with 2 lags of each entering equation (6). As, in its basic form, equation (6) suggests that international effects have the same impact across all countries and, a casual inspection would suggest that this hypothesis is open to question, equation (6) is estimated using alternative estimation techniques to test the robustness to relaxing assumptions around parameter homogeneity.

As this model pools over 75 emerging markets and an 18 year period, the stochastic disturbance $u_{i t}$ in equation (6) requires additional consideration. Reduced form models of this kind typically specify a variance components representation for the disturbance term such that:

$u_{i t}=\eta_{i}+\varepsilon_{i t}$

Where $\eta_{i}$ is a country specific effect and $\varepsilon_{i t}$ represents the country and time specific component of the disturbance. In addition, the country specific effects are assumed fixed, leading to the fixed-effects panel model. One issue that does not receive enough attention is the heterogeneity in variation of growth across emerging markets. Hence assuming a homoscedastic error variance for the $\varepsilon_{i t}$ may be too restrictive. In order to make results more 
interpretable, equation (6) is modified by considering the standardised growth rate of variables. Means are subtracted from each variable - the dependent and all explanatory variables - and scaled by their standard deviation which leads to the transformed variable:

$$
\widetilde{z}_{i t}=\frac{\Delta z_{i t}-\overline{\Delta z_{i}}}{\sigma_{z_{i}}}
$$

The exceptions to this are the common international factors which are already standardised. A further advantage of mean subtraction of all variables is that equation (6) is now free of the country effects $\eta_{i}$ as traditionally invoked in the panel macro literature.

Pooling across the 75 countries in the sample over the period 1992-2009 allows estimation of equation (6) by OLS. As performing OLS with standardised variables is equivalent to producing a 'standardised fixed effects' (SFE) model, these results will be referred to as SFE. Despite being able to deal with heterogeneity in this manner so as to enable straightforward estimation through OLS, it is also reasonable to expect that country responses vary in strength and that the assumption of parameter homogeneity across a large selection of emerging markets is too restrictive. For instance, it is not unreasonable to expect differences in trade and financial integration to drive a different response of a country to international economic shocks e.g. Cameroon may have a different response to an international financial shock to say, South Korea. As Pesaran and Smith (1995) point out, incorrectly imposing such homogeneity also results in biased estimates of the average response. An alternative, especially where observations in the time series dimension are sufficient, is to obtain estimates of such effects through averages of individual time series regressions - the so called 'Mean Group' (MG) estimator. Given the standardisation procedure followed, the MG estimator will be referred to as a 'standardised MG' or 'SMG' estimator in what follows.

Regardless of the method of estimation, equation (6) is a pooled model and parameter estimates only give an indication of the average response and offer relatively less insight into the variation in this response. Yet, understanding variation is as important as understanding the average effect and hence estimating pooled models represents an incomplete picture of global integration. Therefore, in order to test the average results, robustness checks are carried out. Firstly, the pooled model in equation (6) is estimated individually and, relying on incremental R-squares, an assessment is made of the extent to which individual countries show sensitivity 
to international factors. This is a simple test and involves estimating equation (6) with and without the common factors and comparing the adjusted R-squares from the two regressions. This results both in a significance test of the coefficients on the common factors and enables a ranking of countries by addition to R-squares as a result of including the international factors.

\section{Empirical Results}

We start with a brief discussion of our factor model and the ability of the estimated factors to explain the variation in the data. Table 1 displays the correlation between the factors we obtained from estimation of (3) and (4) and the underlying data. As we expect, the global factor displays weak and statistically insignificant correlation with most variables. It is strongly and negatively correlated with movements in the food price index suggesting that it is measuring a narrow channel of international activity. Each of the other three factors strongly and positively correlate with their block variables, although for the commodity price factor correlation with the beverages price index and the energy price index is lower. Similarly, the financial index displays strong correlation with 4 out of the 5 stock indices, from which it is constructed, with only the Japanese stock index displaying more idiosyncratic variation.

\section{$>$ Insert Table 1 here $<$}

Table 2 displays adjusted R-squares obtained from estimating equation 6 over the full sample period 1992-2009. Estimation is carried out on the entire cross-section and also on regional groupings ${ }^{5}$. The table shows adjusted R-squares as well as the contribution from the 4 international factors to the adjusted R-square for both standardised fixed effects (SFE) and standardised mean group (SMG). The adjusted R-square for the full cross-section is low under SFE but rises under SMG. However, the contribution made by the international factors is negligible in both cases suggesting that international shocks have not transmitted to emerging market growth over the period 1992-2009 and country specific factors and policy appear to be the major determinants.

\section{$>$ Insert Table 2 here $<$}

However as the events have shown, the trade and investment flows have been increasing over time leading to greater economic integration of emerging markets with advanced economies.

\footnotetext{
${ }^{5}$ Asia, Eastern Europe and Central Asia (CIS), Latin America and the Caribbean (LAC), Middle East and North Africa (MENA) and Sub Saharan Africa (SSA).
} 
Thus the average results reported for the full sample period 1992-2009 may hide considerable time variation. We therefore partition our sample and re-estimate model (6) for the two subperiods 1992-2001 and 2002-2009. Results for the two time periods and for the full crosssection as well as different regions are presented in Table 3.

\section{$>$ Insert Table 3 here $<$}

Table 3 shows that the adjusted R-square is low for the full cross-section under SFE for the subperiod 1992-2001 and the contribution from the factors is small. While adjusted R-square increases almost three-fold in magnitude under SMG, the factor contribution turns negative. At the regional level, country specific variables have explanatory power for all regions under SMG, but not always under SFE, e.g. Asia, but the contribution of factors remains negligible regardless of estimation method or region. The results suggest that the economic growth in emerging markets displays little sensitivity to international effects on an aggregate basis over the period 1992-2001.

For the second half of the sample period, we see that adjusted R-square increases for the full cross-section as does the partial contribution of the factors. This is more so under SMG where the partial R-square contribution of the factors rises to 0.13 . Looking across regions, there are wide variations. Country specific circumstances continue to play a dominant role in the economic growth for MENA with very little contribution from international factors. Similarly, ASIA as a group displays little sensitivity to international factors. In contrast, LAC and CIS now record much larger sensitivity to international factors, with the partial contribution to adjusted R-square rising to 0.25 and 0.19 respectively under SMG. The findings show that during the latter half (2002-2009), emerging markets show a greater rise in international sensitivity with some regions responding more than others.

So far, we have attempted to deal with heterogeneity through the use of a Mean Group estimator and the creation of regional groupings. As there is no obvious reason for homogeneity within a region, we now inspect partial adjusted R-squares for the full sample period and the two subperiods on a country-by-country basis. In addition, we also examine whether any of the channels captured by the factors plays a particularly significant role. We estimate the model in equation (6) and examine the incremental contribution to adjusted R-squares made by all the factors as well as the incremental contribution of each of the individual factors. We run country 
specific regressions and record the minimum and maximum R-square contributions for the lower quartile, the median and the upper quartile. Results are reported in Table 4.

$>$ Insert Table 4 here $<$

For the full sample period 1992-2009, effects from the four international factors are only visible for the upper quartile. This also holds for the first sub-period 1992-2001 where, there is also less variation in incremental R-squares. In contrast, the inter-quartile range for the second subperiod 2002-2009 is much larger and the median R-sq contribution shifts to the right (it is similar in magnitude to the $3^{\text {rd }}$ quartile results for the full sample), suggesting that international factor effects have been more widely felt in the latter part of our sample period. The maximum $\mathrm{R}$-square contribution is considerably larger for this sub-sample compared to either the full sample period or for the first sub sample period 1992-2001. The activity factor and the global factor have the greatest influence on individual countries during the first half of the sample period.

We find the impact of individual factors to be negligible up to the median for both the full period and for the two sub-periods i.e. no individual factor makes a significant contribution to explanatory power of the growth equation at the median level. Above the median, the impact of the factors starts to increase and is more apparent for the sub-period 2002-2009. Emerging markets above the median display sensitivity to all four factors during this period though the impact of the activity factor is felt more as seen from a greater range of values above the median. The financial factor makes the greatest contribution to adjusted R-square, while the global and the commodity price factors have a lower impact. Of the four factors, the activity factor seems to affect a greater number of countries over 2002-2009 period but the financial factor has had the deepest individual effect.

An R-squared investigation gives an insight into the ability of the factors to explain country specific growth variation, but factors may be relevant to growth even though their explanatory power may remain small. In fact, in adjusted R-squared terms, explanatory power may even 
fall upon addition of factors that nonetheless prove to be significant. We therefore investigate factor coefficients reported in Table $5^{6}$.

\section{$>$ Insert Table 5 here $<$}

Coefficient estimates for the factors are presented for the entire sample period 1992-2009 and also for the two sub-periods 1992-2001 and 2002-2009 in Table 5. There is very little variation in estimates when comparing across the SFE and MG methods. The global factor is negative and significant while the financial and commodity factors are positive and significant under both methods. The activity factor is significant only under SMG. Coefficient estimates based on the time partitioned sample show increases in the global, activity and financial factors when comparing across the two time periods. However, all four factors exhibit significant effects for the second sub sample period 2002-2009 under SMG.

Results for the 5 regions show that growth in Asia, CIS and LAC is more sensitive to the international factors than either for MENA or SSA. Coefficient estimates for the entire sample period show that all 4 factors are significant under SMG for Asia and LAC while for CIS it is only the financial factor that fails to be significant under SMG. Time partitioned results are more varied: the activity factor fails to be significant in the Asian sample for the period 20022009 while it is negative and significant for the full sample period 1992-2001 suggesting that Asian growth has de-coupled from any common G5 activity impulse. The financial and the global factors on the other hand, display large increases in magnitude and statistically significant over the 2002-2009 period. We also find a weakening of the commodity impulse since even though the coefficient under SMG over 2002-2009 is statistically significant; it is lower in magnitude compared to 1992-2001. Thus we find a complex picture of changing interaction. For the CIS, estimates are insignificant for the first part of the sample period whilst 3 out of 4 factors are significant at $5 \%$ for the second sub sample period. Similarly for LAC we find increased integration over time and while the commodity price factor is the only factor significant over 1992-2001 period, all 4 factors display significant coefficients for the second

\footnotetext{
${ }^{6}$ This is also a natural point for a brief mention of coefficients on control variables. While coefficient estimates on the lagged dependent and other country specific control variables are suppressed for brevity, our results show that the coefficient on the first lag of the dependent variable is positive and significant regardless of the estimator chosen. Inflation enters the equation negatively and significantly and is robust to estimation choice supporting the conclusion that inflation above its mean level drives growth below its mean level. Both the trade and the investment ratio enter positively and significantly at least under SMG.
} 
sub sample period 2002-2009 regardless of the estimation method used. For MENA, results are not robust to estimation method and only the financial factor is significant under both SFE and SMG for 2002-2009. The global factor is significant under SMG though the magnitude decline over 2002-2009 compared to 1992-2001. Finally, SSA also shows increasing integration over time at least when using the SMG estimator (this is despite the low R-squared contribution made by the factors in Table 3). Overall, whilst none of the factors display significant coefficients under SMG for 1992-2001 period, all are significant for 2002-2009 which suggests increasing integration for LAC, CIS and SSA. For Asia, the pattern of integration appears to change over time with decoupling from the activity factor, while MENA displays far less integration over time.

While regional proximity provides a convenient way of grouping countries, countries susceptible to international shocks may do so for reasons other than their geographical location. We therefore provide some alternative groupings. We run country specific regressions for the full sample and the two sub-sample periods. We discard those markets that fail to display significant coefficient for none of the factors and then run the SMG regression using a few cross-sectional categorisations. We sort countries into three groups, the first being major commodity exporting countries and include those countries for which exports of commodities account for more than $25 \%$ of all exports. Since this makes no distinction across commodities, the group includes middle to high income oil exporting countries as well as low income agricultural commodity exporting countries for which commodities comprise more than $90 \%$ of exports. The second category comprises the top tier of integrated emerging markets, those that are in the top 10 list of emerging markets in terms of FDI inflows and/or in the top 10 list of emerging markets for merchandise exports ${ }^{7}$. All other countries fall into a third category grouped as 'other'. Our categorisation method creates some overlap as a few countries fall into the list of being both top FDI-exporters and top commodity producers. Where they do, we allow countries to appear in both groups. Our top FDI-exporters group contains 17 countries, our top commodity exporting group consists of 20 countries and our 'other' category consists of 11 countries. Results for the full sample period are shown in Table 6.

$>$ Insert Table 6 here $<$

\footnotetext{
${ }^{7}$ FDI flow data are taken from UNCTAD (2009), merchandise and commodity export data from WTO(2009).
} 
We find that coefficients on both the financial and the commodity factor are greater in magnitude for top FDI-exporting countries when compared to the countries in 'other' category. Major commodity exporting countries record the greatest sensitivity to the commodity factor while the coefficient on the activity factor is significant only for the 'other' category. The global factor is negative and statistically significant for all groups and greatest in magnitude for the 'other' category.

In Table 7, we show the countries for which we find significant coefficient for at least one of the four factors for the full period 1992-2009. We observe that commodity price factor has the most widespread effect on growth with significant coefficients appearing for 30 countries in the sample. Other factors have less widespread effect with the financial factor significant for only 12 countries and the activity factor for 7 countries. The global factor also has limited impact and appears significantly for only 9 countries. It is interesting to note that 11 out of the 19 LAC countries in the sample display significant commodity price effects, making them most sensitive to common movements in commodity prices. This is followed by 7 SSA countries, 5 Asian, 4 CIS and 3 MENA countries. As we have controlled for country specific inflation, our regressions capture the direct effect of commodity prices on growth. As a result, it is not surprising to see that the direct effect is positive for all countries (except Kazakhstan).

The financial factor is positive and significant for a number of emerging markets with relatively liberal and mature financial markets and also positive and significant for a few emerging markets with repressed financial markets (Egypt, Nicaragua and Argentina).

Sensitivity to the activity factor is rather limited and less clear-cut evidence with 3 countries showing negative coefficients and 4 showing positive coefficients. While the small number of countries that respond to the G5 activity factor suggests that emerging markets are not very closely linked to the activity cycle of the G5, the negative results also show that a very few emerging markets have also managed to respond counter-cyclically to G5 activity. The results offer an interesting contrast with those reported earlier in Table 3. Whilst only 7 countries display significant coefficients on the activity factor in Table 7, results reported in Table 3 suggest that the activity factor had the most widespread impact on growth in terms of contribution to R-square. In interpreting results, we favour the more conservative interpretation provided by the coefficient estimates in Table 7. 
Finally, a very few emerging markets respond to the global factor and all of them do so countercyclically which is intuitively plausible given the negative correlation with international food prices.

\section{$>$ Insert Table 7 here $<$}

We investigate further the time varying sensitivity to the global factor. Our earlier analysis shows that for a few countries adjusted R-square was considerably higher in the latter half of the sample period. While we acknowledge the somewhat arbitrary nature of the sample split, we do base on the evidence that the pace of trade and financial integration with global economy has increased during the period since 2001 onwards. Thus, the hypothesis is that a group of emerging markets have become more sensitive to global shocks and this sensitivity has increased since 2002. This is clearly contrary to the standard view of de-coupling and we would like to test whether these views are reconcilable. An alternative hypothesis that provides a more nuanced view of de-coupling but derived from our results so far is that the increased sensitivity we see is consistent with a certain view of de-coupling but also reflects a response to a specific shock over the period 2002-2009. The specific shock we are concerned about is the 'credit crisis' which we view as a tail event and our alternative testable hypothesis is that while emerging markets remain de-coupled from international influences, transmission of international shocks increases when a large negative event like 'credit crisis' occur.

We provide a simple test of the 'credit crisis' hypothesis by creating a credit crisis time dummy which takes the value 1 from 2007Q 4 to the end of our sample period and 0 otherwise ${ }^{8}$. The time dummy is interacted with each of the international factors, creating 4 new variables that are included in model (6) and enable us a test of parameter stability over the crisis period. We estimate model (6) over the entire sample period and also over the second sample period 200209. If the results reported earlier for 2002-09 period are purely due to increased sensitivity over the crisis period, the coefficient for the factors interacted with credit crisis dummy should be statistically significant.

$>$ Insert Table 8 here $<$

\footnotetext{
${ }^{8}$ We select $2007 \mathrm{Q} 4$ as the start date for our credit crisis dummy as the USA officially entered into recession in this quarter per the NBER: http://www.nber.org/
} 
Coefficient estimates using SFE and SMG regressions for international factors and for factors interacted with the credit crisis time dummy are shown in Table 8. While global, financial and commodities factors are significant under SFE for the full sample period, the global factor loses significance under SMG. The financial factor interacted with the credit crisis time dummy is positive and statistically significant under both estimation methods with a higher coefficient under SMG. The magnitude of the coefficient, under either estimation method, is high compared to the coefficient estimate on the financial factor alone. The financial factor seems to have had further and a particularly strong effect during the credit crisis. A similar strong, significant effect is observed for the commodities factor but the sign of the coefficient is negative contrary to our earlier findings and suggesting of an unusual impact during the credit crisis.

\section{$>$ Insert Table 9 here $<$}

Finally, to examine how widespread credit crisis effects are, we report results for individual countries only where we find a significant factor coefficient for the factors interacted with the 'credit crisis' dummy. From results reported in Table 9, we find that 26 countries have significant coefficients during the credit crisis period for the financial factor. Next in terms of widespread impact is the commodity price factor for which 10 countries show a significant interaction effects. However, only 2 countries display significant coefficients to the activity factor and to the global factor. The sign of the coefficient on the financial factor is always positive in all 26 markets and is considerably higher than 1 in several cases. As G5 stock markets fell strongly over this period and then subsequently recovered, growth in these 26 emerging markets tracked this movement closely, often in greater magnitude (in sample standard deviation terms). Not all countries that record significant financial factor effects over the entire sample period display excess sensitivity during the credit crisis, in fact we only note this for 5 countries - Bahrain, Nicaragua, Hong Kong, Singapore and Turkey. The excess sensitivity to the commodity price factor is negative for all countries except the Philippines, suggesting that these countries displayed counter-cyclical performance to commodity prices over this period. Of the countries sensitive to our credit crisis commodity factor, only 3 display sensitivity over the 2002-09 period per Table 5. The dummy term suggests an unusual response of most countries during the credit crisis i.e., that while growth in these countries has generally been unresponsive to commodity price movements, the period 2007-2009 resulted in a negative relationship as falling commodity prices boosted growth. For the three countries that also show 
sensitivity over the period 2002-2009, we note that the Philippines displays a greater positive response during the credit crisis while Ukraine and Cambodia display positive responses during the 2002-2009 period as a whole but a negative response during 2007-2009. For the latter two countries, the findings suggest a downward impact on growth during years of commodity price increases but a stronger positive effect during periods of commodity price decreases. Overall, we find that simple aggregations do not appear to be sufficient to explain the impact of international commodity price movements on emerging markets' growth.

\section{Conclusions}

The paper's aim is to provide empirical evidence on the extent and channels of transmission of international shocks on the economic growth of emerging markets. Using a large sample of 75 emerging markets we find that international factors have very limited ability to explain growth in the emerging markets over the period 1992-2009. However, there is considerable variation both over time, over cross-section and across factors suggesting that any conclusions drawn on the basis of average results may be an over-simplification of the reality. When we split our sample by time period, we find greater effects of the international factors on the emerging markets' growth during the period 2002-09. Across regions, this is most evident for CIS \& LAC. While we also find some increase in adjusted R-squares for Asia and SSA (compared to the first half of the sample period 1992-2001), markets in the MENA region appear to be insulated.

We find evidence of cross sectional heterogeneity and the 'fat tail effects'. While, factor Rsquare contributions are close to zero for the period 1992-2001 period, we find some increase in R-square contribution for countries above the third quartile. For the second half of the sample period 2002-2009 which includes 'credit crisis, we see a fatter and longer tail when looking at R-square contributions. This seems to be because of the increased effect of activity and financial factors over this period. Also, we find that several emerging markets show increased sensitivity to G5 activity which contradicts the de-coupling hypothesis. The activity effect is noticeable above the median for the second half of the sample period with a longer and fatter tail in sensitivity to G5 activity. Notably, financial spill-overs matter though the effects seem to be felt by a smaller number of countries than the activity factor. Thus coupling is more generally observed through the activity factor across the cross-section while the influence of financial effects is somewhat limited. However, in terms of magnitude, the effects of the financial factor seem to be quite large. 
The R-square analysis shows that Asia is relatively decoupled, though adjusted R-square show an increase over the 2002-2009 period. On the contrary, CIS and LAC are more coupled to the activity factor. Coefficient estimates permit a closer investigation and confirm that the coefficient on the activity factor increases in magnitude and is significant for CIS and LAC over the period 2002-2009 period. For Asia however, the negative and significant coefficients turn positive but remain small and statistically insignificant when compared across the two subperiods. This may suggest that the emerging markets in Asia are decoupling.

Overall, the activity factor is significant over the second half 2002-2009 but this could be simply reflecting the credit crisis effect. However when we control for the credit crisis effect, we find that this is not the case. The coefficient estimate on the G5 economic activity factor survives the inclusion of the credit crisis dummy. Coefficient estimates on the commodity factor without a credit crisis dummy show a positive and statistically significant effect on emerging markets' growth. Though the commodity effects seem to be time-invariant, they are not robust to the inclusion of a credit crisis dummy. In fact we see de-coupling from the commodity price factor for most of the countries during the second half of the sample period. However, the sensitivity to large commodity shocks remains.

Finally, coefficient estimates on the financial factor show a positive and significant effect that survives the credit crisis dummy confirming that G5 financial shocks transmit to emerging markets' growth. This result is more robust in the second half of the sample period 2002-2009 which may suggest that emerging markets are showing increased integration with the global market over time. 


\section{References:}

Akin, C. and Kose, A.M., 2007. Changing nature of North-South linkages: stylised facts and explanations. IMF working paper WP/07/280.

Arora, V. and Vamvakidis, A., 2001. The impact of U.S. economic growth on the rest of the world: How much does it matter? IMF Working Paper WP/01/119.

Burk men, S.P., Gelos, G., Renhack, R., and Walsh, J.P., 2012. The global financial crisis: explaining cross-country differences in the output impact. Journal of International Money and Finance 31, 42-59.

Bui, T., and Bayoumi, T., 2010. Their cup spilleth over. Finance and Development, March 2010, 32-34.

Baxter, M., and Kouparitsas, M.A., 2004. Determinants of business cycle comovement: a robust analysis. Journal of Monetary Economics 52, 113-157.

Burstein, A., Kurz, C., and Tesar, L., 2008. Trade, production sharing, and the international transmission of business cycles. Journal of Monetary Economics 55, 775-795.

Canova, F., 2005. The Transmission of US Shocks to Latin America. Journal of Applied Econometrics 20, 229-251.

Chambet, A. and Gibson, R., 2008. Financial integration, economic instability and trade structure in emerging markets $27,654-675$.

Didier, T., Hevia, C., and Schmukler, S., 2012. How resilient and countercyclical were emerging economies during the global financial crisis. Journal of International Money and Finance (forthcoming), 1-26.

Dooley, M., and Hutchinson, M., 2009. Transmission of the U.S. subprime crisis to emerging markets: Evidence on the decoupling-recoupling hypothesis. Journal of International Money and Finance 28,1331-1349

Economist, 2012. The great slowdown: A sticky spell for the emerging world carries warnings for its long-term growth, July.

Edwards, S., 2010. The international transmission of interest rate shocks: The Federal Reserve and emerging markets in Latin America and Asia 29, 685-703.

Fidrmuc, J., and Korhonen, L., 2010. The impact of the global financial crisis on business cycles in Asian emerging economies. Journal of Asian Economics 21, 293-303.

Forni, M., Lippi, M., Reichlin, L., Altissimo, F. and Bassanetti, A, 2003. Eurocoin: A Real Time Coincident Indicator Of The Euro Area Business Cycle. Computing in Economics and Finance 2003 242, Society for Computational Economics.

Genberg, H., 2003. Foreign versus Domestic Factors as Sources of Macroeconomic Fluctuations in Hong Kong. HEI Working Paper No. 5. 
IMF, April 2009. World Economic Outlook, 4-5.

Kose, A.M., Otrok, C. and Prasad, E., 2008. Global business cycles: convergence or decoupling. Deutsche Bundesbank Discussion Paper. Series 1 Economic Studies, No 17/2008.

Kouparitsas, M., 2001. Evidence of the North--South business cycle. Economic Perspectives, Vol 25, Issue1, pgs.

Levine, R. and Renelt, D. 1992. A Sensitivity Analysis of Cross-Country Growth Regressions," American Economic Review 82(4), 942-963.

Pesaran, H.M. and Smith, R., 1995. Estimating long run relationships from dynamic heterogeneous panels. Journal of Econometrics. Vol 68(1), 79-113.

Rand, J., and Tarp, F., 2002. Business Cycles in Developing Countries: Are They Different? World Development Vol. 30, No. 12, 2071-2088,

Temple, J., 1999. The new growth evidence. Journal of Economic Literature, 37(1), 112156.

WTO, 2009. World Trade Report, Trade in a Globalising World. WTO, 3-4. 
Table 1

Correlation between factors and underlying variables

\begin{tabular}{|c|c|c|c|c|c|c|c|c|c|c|}
\hline \multicolumn{11}{|l|}{ Activity } \\
\hline & deugdp & deuimp & fragdp & fraimp & gbrgdp & gbrimp & jpngdp & jprimp & usagdp & usaimp \\
\hline Global Factor & -0.06 & 0.18 & -0.08 & 0.06 & -0.11 & 0.00 & -0.22 & 0.20 & -0.03 & 0.20 \\
\hline Activity Factor & 0.75 & 0.66 & 0.88 & 0.88 & 0.89 & 0.68 & 0.55 & 0.60 & 0.74 & 0.84 \\
\hline \multicolumn{11}{|l|}{ Financial } \\
\hline & deustx & frastx & gbrstx & jpnstx & usastx & & & & & \\
\hline Global Factor & 0.15 & 0.15 & 0.07 & -0.05 & 0.14 & & & & & \\
\hline Financial Factor & 0.95 & 0.98 & 0.77 & 0.55 & 0.85 & & & & & \\
\hline \multicolumn{11}{|l|}{ Commodity Prices } \\
\hline & agmat & bev & food & indmat & metal & nonfuel & energy & & & \\
\hline Global Factor & -0.05 & -0.21 & -0.88 & -0.12 & -0.13 & -0.53 & -0.28 & & & \\
\hline Commodity Factor & 0.81 & 0.36 & 0.59 & 1.00 & 0.93 & 0.92 & 0.66 & & & \\
\hline
\end{tabular}

Table 2

Factor contributions using Standardised Fixed Effects (SFE) and Mean Group (MG) for the full sample period 1992-2009 for all regions

\begin{tabular}{|l|lc|lc|}
\hline & \multicolumn{2}{|c|}{ SFE } & \multicolumn{2}{c|}{ Mean Group } \\
\hline & \multicolumn{3}{|c|}{ Rsq } & Factor contribution \\
Region & Rsq & Factor contribution & Rsq & 0.044 \\
ALL & 0.224 & 0.033 & 0.398 & 0.024 \\
ASIA & 0.200 & 0.045 & 0.361 & 0.081 \\
CIS & 0.145 & 0.076 & 0.297 & 0.089 \\
LAC & 0.167 & 0.085 & 0.318 & 0.007 \\
MENA & 0.456 & 0.017 & 0.491 & 0.004 \\
SSA & 0.494 & 0.014 & 0.550 & \\
\hline
\end{tabular}

Note: Asia includes Asian countries, CIS includes countries from Eastern Europe and Central Asia, LAC includes countries from Latin America and the Caribbean, MENA includes countries from Middle East and North Africa, and SSA includes countries from Sub-Saharan Africa. 
Table 3

Factor contributions for all regions using Standardised Fixed Effects (SFE) and Mean Group (MG) for the full sample period 1992-2009 and second sample period 2002-2009

\begin{tabular}{|c|c|c|c|c|c|c|c|c|}
\hline & \multicolumn{4}{|c|}{$1992-2001$} & \multicolumn{4}{|c|}{$2002-2009$} \\
\hline & & SFE & & Mean Group & & SFE & & an Group \\
\hline Region & Rsq & $\begin{array}{l}\text { Factor } \\
\text { contribution }\end{array}$ & Rsq & $\begin{array}{l}\text { Factor } \\
\text { contribution }\end{array}$ & Rsq & $\begin{array}{l}\text { Factor } \\
\text { contribution }\end{array}$ & Rsq & $\begin{array}{l}\text { Factor } \\
\text { contribution }\end{array}$ \\
\hline ALL & 0.115 & 0.028 & 0.3 & -0.01 & 0.302 & 0.071 & 0.515 & 0.131 \\
\hline ASIA & 0.004 & -0.004 & 0.3 & 0.01 & 0.228 & 0.073 & 0.465 & 0.076 \\
\hline CIS & 0.065 & 0.017 & 0.19 & -0.02 & 0.282 & 0.134 & 0.499 & 0.193 \\
\hline LAC & 0.330 & 0.006 & 0.17 & -0.03 & 0.285 & 0.155 & 0.532 & 0.249 \\
\hline MENA & 0.475 & 0.003 & 0.42 & 0.01 & 0.571 & 0.014 & 0.529 & 0.034 \\
\hline SSA & 0.130 & 0.004 & 0.48 & -0.01 & 0.544 & 0.035 & 0.551 & 0.059 \\
\hline
\end{tabular}

Note: Asia includes Asian countries, CIS includes countries from Eastern Europe and Central Asia, LAC includes countries from Latin America and the Caribbean, MENA includes countries from Middle East and North Africa, and SSA includes countries from Sub-Saharan Africa.

\section{Table 4}

Partial R squares for the full sample (1992-2009) and two sub periods 1992-2001 and 2002-2009.

\begin{tabular}{|l|l|ccccc|}
\hline & & All factors & \multicolumn{1}{c}{ Global } & Activity & Financial & Commodities \\
\hline $1992-09$ & minimum & -0.092 & -0.035 & -0.037 & -0.033 & -0.037 \\
& q1 & -0.012 & -0.008 & -0.013 & -0.009 & -0.011 \\
& median & 0.012 & 0.000 & 0.000 & -0.003 & 0.001 \\
& q3 & 0.085 & 0.015 & 0.025 & 0.012 & 0.020 \\
& maximum & 0.361 & 0.113 & 0.324 & 0.213 & 0.136 \\
\hline $1992-01$ & minimum & -0.200 & -0.064 & -0.051 & -0.078 & -0.035 \\
& q1 & -0.053 & -0.021 & -0.022 & -0.027 & -0.019 \\
& median & -0.010 & -0.008 & -0.010 & -0.013 & -0.006 \\
& q3 & 0.020 & 0.009 & 0.004 & 0.001 & 0.010 \\
& maximum & 0.255 & 0.147 & 0.171 & 0.091 & 0.200 \\
\hline $2002-09$ & minimum & -0.221 & -0.079 & -0.088 & -0.089 & -0.098 \\
& q1 & 0.007 & -0.019 & -0.016 & -0.020 & -0.025 \\
& median & 0.076 & 0.000 & 0.007 & 0.007 & 0.010 \\
& q3 & 0.239 & 0.052 & 0.111 & 0.040 & 0.049 \\
& maximum & 0.719 & 0.334 & 0.504 & 0.633 & 0.279 \\
\hline
\end{tabular}


Table 5

Factors coefficients under Standardised Fixed Effects (SFE) and Mean Group (MG) for the full sample (1992-2009) and two sub periods, 1992-2001 and 2002-2009

\begin{tabular}{|c|c|c|c|c|c|c|c|}
\hline & & $\begin{array}{l}1992- \\
2009 \\
\end{array}$ & $\begin{array}{c}\text { SFE } \\
1992- \\
2001 \\
\end{array}$ & $\begin{array}{c}2002- \\
2009 \\
\end{array}$ & $\begin{array}{c}1992- \\
2009 \\
\end{array}$ & $\begin{array}{l}\text { SMG } \\
1992- \\
2001 \\
\end{array}$ & $\begin{array}{l}2002- \\
2009\end{array}$ \\
\hline \multirow[t]{4}{*}{ All } & Global & $-0.06 * *$ & $-0.01 * *$ & $-0.1 * *$ & $-0.06 * *$ & 0.00 & $-0.12 * *$ \\
\hline & Activity & 0.01 & -0.003 & 0.07 & $0.02 * *$ & -0.01 & $0.09 * *$ \\
\hline & Financial & $0.08 * *$ & $0.04 * *$ & $0.14 * *$ & $0.07 * *$ & 0.03 & $0.11^{* *}$ \\
\hline & Commodities & $0.11 * *$ & $0.08 * *$ & $0.05 * *$ & $0.12 * *$ & $0.08 * *$ & $0.08 * *$ \\
\hline \multirow[t]{4}{*}{ Asia } & Global factor & -0.04 & 0 & $-0.11 * *$ & $-0.05 *$ & -0.01 & $-0.15^{* *}$ \\
\hline & Activity & $-0.06 * *$ & $-0.12 * *$ & 0.01 & $-0.07 * *$ & $-0.17 * *$ & 0.03 \\
\hline & Financial & $0.18 * *$ & $0.15 * *$ & $0.25 * *$ & $0.14 * *$ & $0.08^{*}$ & $0.23 * *$ \\
\hline & Commodities & $0.11 * *$ & $0.18 * *$ & 0.02 & $0.13 * *$ & $0.16^{* *}$ & $0.06^{*}$ \\
\hline \multirow[t]{4}{*}{ CIS } & Global factor & $-0.11 * *$ & 0.03 & $-0.17 * *$ & $-0.09 * *$ & 0.08 & $-0.18 * *$ \\
\hline & Activity & $0.16^{* *}$ & 0.06 & $0.21 * *$ & $0.15^{* *}$ & 0.09 & $0.21 * *$ \\
\hline & Financial & $0.06^{*}$ & 0.02 & $0.16^{* *}$ & 0.05 & 0.04 & $0.14^{* *}$ \\
\hline & Commodities & $0.1 * *$ & 0.05 & 0 & $0.11 * *$ & 0.06 & 0.02 \\
\hline \multirow[t]{4}{*}{ LAC } & Global factor & $-0.07 * *$ & -0.05 & $-0.1 * *$ & $-0.08 * *$ & -0.04 & $-0.12 * *$ \\
\hline & Activity & $0.07 * *$ & 0 & $0.16^{* *}$ & $0.05 * *$ & 0 & $0.12 * *$ \\
\hline & Financial & $0.05^{*}$ & 0.04 & $0.08 *$ & $0.06^{* *}$ & 0.03 & $0.07 *$ \\
\hline & Commodities & $0.2 * *$ & $0.22 * *$ & $0.12 * *$ & $0.19 * *$ & $0.15 * *$ & $0.13 * *$ \\
\hline \multirow[t]{4}{*}{ MENA } & Global factor & $-0.08 * *$ & -0.12 & -0.06 & $-0.1 * *$ & $-0.14 * *$ & $-0.07 *$ \\
\hline & Activity & -0.02 & 0.06 & -0.01 & -0.03 & -0.01 & 0.02 \\
\hline & Financial & $0.09 * *$ & 0.06 & $0.11^{* *}$ & $0.1^{* *}$ & 0.08 & $0.07^{*}$ \\
\hline & Commodities & 0.05 & 0.03 & 0.02 & $0.05 *$ & 0.01 & 0.06 \\
\hline \multirow[t]{4}{*}{ SSA } & Global factor & -0.02 & 0.05 & $-0.06^{* *}$ & -0.02 & 0.06 & $-0.06 * *$ \\
\hline & Activity & 0 & 0.07 & 0 & 0.01 & 0.04 & $0.05^{* *}$ \\
\hline & Financial & 0 & $-0.08 * *$ & $0.07 * *$ & 0 & -0.04 & $0.05^{*}$ \\
\hline & Commodities & $0.1 * *$ & -0.02 & $0.08 * *$ & $0.09 * *$ & -0.01 & $0.08 * *$ \\
\hline
\end{tabular}

Note: Significant at 5\%**, significant at 10\%*. Asia includes Asian countries, CIS includes countries from Eastern Europe and Central Asia, LAC includes countries from Latin America and the Caribbean, MENA includes countries from Middle East and North Africa, and SSA includes countries from Sub-Saharan Africa.

Table 6

Factors coefficients for the full sample (1992-2009) for countries grouped on the basis of major commodity exporting countries, major foreign direct investment (FDI) recipient and merchandise exporting countries, and other countries which are neither major commodity exporting nor do they receive high level of FDI

\begin{tabular}{|l|ccc|}
\hline & & & \\
& & & \\
& & & \\
& Major Commodity Exporters & Top FDI recipients and Exporters & Other \\
\hline Global & $-0.05^{* *}$ & $-0.10^{* *}$ & $-0.15^{* *}$ \\
Activity & 0.01 & -0.02 & $0.11^{* *}$ \\
Financial & $0.05^{* *}$ & $0.17^{* *}$ & $0.05^{* *}$ \\
Commodities & $0.16^{* *}$ & $0.2^{* *}$ & $0.11^{* *}$ \\
\hline
\end{tabular}


Note: Significant at $5 \% * *$, significant at $10 \% *$.

\section{Table 7}

Countries that show their GDP growth sensitivity to Global, Activity, Financial or commodity factors during the entire sample period 1992-2009

\begin{tabular}{|c|c|c|c|c|c|}
\hline \multicolumn{2}{|r|}{ Global } & \multicolumn{2}{|r|}{ Financial } & \multicolumn{2}{|r|}{ Commodity Price } \\
\hline BOL & $-0.419 * *$ & ARG & $0.249 * *$ & DOM & $0.343^{* *}$ \\
\hline CZE & $-0.181^{*}$ & BHR & $0.145^{* *}$ & EGY & $0.171^{* *}$ \\
\hline $\mathrm{MAF}$ & $-0.236^{*}$ & EGY & $0.14^{* *}$ & GAB & $0.168^{* *}$ \\
\hline SVK & $-0.282 * *$ & EST & $0.231^{*}$ & GTM & $0.202^{* *}$ \\
\hline SVN & $-0.289 * *$ & $\mathrm{HKG}$ & $0.302^{* *}$ & HKG & $0.366^{* *}$ \\
\hline TUN & $-0.197 *$ & KOR & $0.218^{*}$ & HND & $0.224^{* *}$ \\
\hline UKR & $-0.177^{*}$ & MEX & $0.259^{* *}$ & IRN & $0.122^{*}$ \\
\hline URY & $-0.283 * *$ & NIC & $0.158^{*}$ & JAM & $0.143^{* *}$ \\
\hline VNN & $-0.37 * *$ & SGP & $0.388^{* *}$ & KAZ & $-0.237^{*}$ \\
\hline \multicolumn{2}{|r|}{ Activity } & TUR & $0.394^{* *}$ & KEN & $0.09^{*}$ \\
\hline \multirow{12}{*}{$\begin{array}{l}\text { CHN } \\
\text { EGY } \\
\text { LVA } \\
\text { SEN } \\
\text { SGP } \\
\text { SVK } \\
\text { SVN }\end{array}$} & $-0.178^{*}$ & TWI & $0.497 * *$ & KHM & $0.193^{* *}$ \\
\hline & $-0.131 * *$ & VNN & $0.274 *$ & MYS & $0.373^{* *}$ \\
\hline & $0.303 * *$ & & Commodity Price & PER & $0.366^{* *}$ \\
\hline & $0.147^{*}$ & $\mathrm{BOL}$ & $0.217^{* *}$ & PHL & $0.299 * *$ \\
\hline & $-0.186^{*}$ & BRA & $0.27 * *$ & PRY & $0.406^{* *}$ \\
\hline & $0.322^{* *}$ & $\mathrm{BW}$ & $0.207^{*}$ & RUS & $0.357^{* *}$ \\
\hline & $0.451^{* *}$ & $\mathrm{CHN}$ & $0.227^{*}$ & SDN & $0.149^{*}$ \\
\hline & & $\mathrm{CMI}$ & $0.053^{* *}$ & SLV & $0.16^{* *}$ \\
\hline & & $\mathrm{COD}$ & $0.053^{* *}$ & TUR & $0.211^{*}$ \\
\hline & & CRI & $0.261^{* *}$ & UKR & $0.159^{*}$ \\
\hline & & $\mathrm{CZE}$ & $0.313^{* *}$ & URY & $0.213^{*}$ \\
\hline & & & & ZAF & $0.292^{* *}$ \\
\hline
\end{tabular}

Note: Significant at $5 \%{ }^{* *}$, significant at $10 \% *$.

Table 8

Results for parameter stability using credit crisis time dummy for the entire sample period 1992-2009 and second sub period 2002-2009.

\begin{tabular}{|l|ll|ll|}
\hline & \multicolumn{2}{|c|}{$1992-09$} & \multicolumn{2}{c|}{$2002-09$} \\
& SFE & SMG & SFE & SMG \\
\hline Global & $-0.03^{*}$ & -0.02 & -0.04 & -0.03 \\
Activity & -0.01 & -0.01 & $0.09^{* *}$ & $0.08^{* *}$ \\
Financial & $0.06^{* *}$ & $0.04^{* *}$ & $0.10^{* *}$ & $0.04^{* *}$ \\
Commodities & $0.08^{* *}$ & $0.08^{* *}$ & -0.01 & 0.02 \\
Global*Tdum & -0.04 & -0.04 & $-0.08^{* *}$ & -0.12 \\
Activity*Tdum & 0.08 & $0.08^{*}$ & -0.02 & 0.03 \\
Financial*Tdum & $0.34^{* *}$ & $0.44^{* *}$ & $0.39^{* *}$ & $0.43^{* *}$ \\
commodities*Tdum & $-0.17^{* *}$ & $-0.17^{* *}$ & $-0.16^{* *}$ & $-0.15^{* *}$ \\
Adjusted R-square & 0.18 & 0.39 & 0.27 & 0.50 \\
\hline
\end{tabular}

Note: Significant at 5\%**, significant at $10 \% *$. Tdum represents the credit crisis time dummy which takes the value of 1 from the $4^{\text {th }}$ quarter of 2007 till the end of sample period in 2009. 


\section{Table 9}

Factor coefficients for the interaction terms only from individual country regressions for the entire sample period 1992-2009

\begin{tabular}{|c|c|c|c|c|c|c|c|c|c|}
\hline \multicolumn{2}{|c|}{ Global } & \multicolumn{2}{|c|}{ Activity } & \multicolumn{2}{|c|}{ Financial } & & & \multicolumn{2}{|c|}{ Commodity Prices } \\
\hline SVN & $-0.665 * *$ & KHM & $-0.416 * *$ & CMR & $0.243 * *$ & MYS & $1.036^{* *}$ & TWN & $-0.894 * *$ \\
\hline \multirow[t]{12}{*}{ HUN } & $-0.445 * *$ & TWN & $0.835^{*}$ & COD & $0.243 * *$ & TUR & $1.045^{* *}$ & POL & $-0.677 * *$ \\
\hline & & & & AGO & $0.413 * *$ & SLV & $1.05 * *$ & HRV & $-0.648 *$ \\
\hline & & & & EGY & $0.626 * *$ & NIC & $1.11 * *$ & GHA & $-0.612 * *$ \\
\hline & & & & CZE & $0.648^{*}$ & LVA & $1.14 * *$ & BWA & $-0.477 *$ \\
\hline & & & & JAM & $0.678 * *$ & $\mathrm{HKG}$ & $1.231 * *$ & HUN & $-0.45 * *$ \\
\hline & & & & TZA & $0.717 * *$ & SVK & $1.246 * *$ & KHM & $-0.386 * *$ \\
\hline & & & & BHR & $0.742 * *$ & HUN & $1.275^{* *}$ & UKR & $-0.345^{*}$ \\
\hline & & & & HND & $0.769 * *$ & UKR & $1.33 * *$ & TZA & $-0.224 * *$ \\
\hline & & & & ECU & $0.89 *$ & SGP & $1.36 * *$ & PHL & $0.649 *$ \\
\hline & & & & PHL & $0.891 *$ & GHA & $1.642 * *$ & & \\
\hline & & & & GTM & $0.896^{* *}$ & KHM & $1.734 * *$ & & \\
\hline & & & & SAU & $1.035^{* *}$ & BWA & $2.163 * *$ & & \\
\hline
\end{tabular}

Note: Significant at $5 \% * *$, significant at $10 \% *$ 
Appendix A

\begin{tabular}{|c|c|c|c|}
\hline & ISO code & country name & Region \\
\hline 1 & AGO & Angola & SSA \\
\hline 2 & ARG & Argentina & LAC \\
\hline 3 & AZE & Azerbaijan & CIS \\
\hline 4 & BGD & Bangladesh & ASIA \\
\hline 5 & BGR & Bulgaria & $\mathrm{CIS}$ \\
\hline 6 & BHR & Bahrain & MENA \\
\hline 7 & BOL & Bolivia & LAC \\
\hline 8 & BRA & Brazil & LAC \\
\hline 9 & BWA & Botswana & SSA \\
\hline 10 & $\mathrm{CHL}$ & Chile & LAC \\
\hline 11 & $\mathrm{CHN}$ & China & ASIA \\
\hline 12 & CIV & Ivory Coast & SSA \\
\hline 13 & CMR & Cameroon & SSA \\
\hline 14 & COL & Colombia & LAC \\
\hline 15 & CRI & Costa Rica & LAC \\
\hline 16 & CZE & Czech Rep & $\mathrm{CIS}$ \\
\hline 17 & DOM & Dominican Rep & LAC \\
\hline 18 & $\mathrm{ECU}$ & Ecuador & LAC \\
\hline 19 & EGY & Egypt & MENA \\
\hline 20 & EST & Estonia & $\mathrm{CIS}$ \\
\hline 21 & ETH & Ethiopia & SSA \\
\hline 22 & GAB & Gabon & SSA \\
\hline 23 & GHA & Ghana & SSA \\
\hline 24 & GTM & Guatemala & LAC \\
\hline 25 & HKG & Hong Kong & ASIA \\
\hline 26 & HND & Honduras & LAC \\
\hline 27 & HRV & Croatia & $\mathrm{CIS}$ \\
\hline 28 & HUN & Hungary & $\mathrm{CIS}$ \\
\hline 29 & IDN & Indonesia & ASIA \\
\hline 30 & IND & India & ASIA \\
\hline 31 & IRN & Iran & MENA \\
\hline 32 & JAM & Jamaica & LAC \\
\hline 33 & JOR & Jordan & MENA \\
\hline 34 & $\mathrm{KAZ}$ & Kazakhstan & $\mathrm{CIS}$ \\
\hline 35 & KEN & Kenya & SSA \\
\hline 36 & KHM & Cambodia & ASIA \\
\hline 37 & KOR & Rep_Korea & ASIA \\
\hline 38 & LAO & Laos & ASIA \\
\hline 39 & LKA & Sri Lanka & ASIA \\
\hline
\end{tabular}




$\begin{array}{llll}40 & \text { LVA } & \text { Latvia } & \text { CIS } \\ 41 & \text { MAR } & \text { Morocco } & \text { MENA } \\ 42 & \text { MEX } & \text { Mexico } & \text { LAC } \\ 43 & \text { MLI } & \text { Mali } & \text { SSA } \\ 44 & \text { MRT } & \text { Mauritania } & \text { SSA } \\ 45 & \text { MUS } & \text { Mauritius } & \text { SSA } \\ 46 & \text { MYS } & \text { Malaysia } & \text { ASIA } \\ 47 & \text { NGA } & \text { Nigeria } & \text { SSA } \\ 48 & \text { NIC } & \text { Nicaragua } & \text { LAC } \\ 49 & \text { NPL } & \text { Nepal } & \text { ASIA } \\ 50 & \text { PAK } & \text { Pakistan } & \text { ASIA } \\ 51 & \text { PAN } & \text { Panama } & \text { LAC } \\ 52 & \text { PER } & \text { Peru } & \text { LAC } \\ 53 & \text { PHL } & \text { Philippines } & \text { ASIA } \\ 54 & \text { POL } & \text { Poland } & \text { CIS } \\ 55 & \text { PRY } & \text { Paraguay } & \text { LAC } \\ 56 & \text { RUS } & \text { Russia } & \text { CIS } \\ 57 & \text { SAU } & \text { Saudi Arabia } & \text { MENA } \\ 58 & \text { SDN } & \text { Sudan } & \text { SSA } \\ 59 & \text { SEN } & \text { Senegal } & \text { SSA } \\ 60 & \text { SGP } & \text { Singapore } & \text { ASIA } \\ 61 & \text { SLV } & \text { El Salvador } & \text { LAC } \\ 62 & \text { SVK } & \text { Slovak Republic } & \text { CIS } \\ 63 & \text { SVN } & \text { Slovenia } & \text { CIS } \\ 64 & \text { SYR } & \text { Syria } & \text { MENA } \\ 65 & \text { TUN } & \text { Tunisia } & \text { MENA } \\ 66 & \text { TUR } & \text { Turkey } & \text { MENA } \\ 67 & \text { TWN } & \text { Taiwan } & \text { ASIA } \\ 68 & \text { TZA } & \text { Tanzania } & \text { SSA } \\ 69 & \text { UGA } & \text { Uganda } & \text { SSA } \\ 70 & \text { UKR } & \text { Ukraine } & \text { CIS } \\ 71 & \text { URY } & \text { Uruguay } & \text { LAC } \\ 72 & \text { VEN } & \text { Venezuela } & \text { LAC } \\ 73 & \text { VNM } & \text { Vietnam } & \text { ASIA } \\ 74 & \text { ZAF } & \text { South Africa } & \text { SSA } \\ 75 & \text { ZMB } & \text { Zambia } & \text { SSA }\end{array}$




\section{Appendix B}

\section{Activity variables}

$\begin{array}{ll}\text { USAGDP } & \text { USA real GDP growth (quarterly log difference) } \\ \text { JPNGDP } & \text { Japan real GDP growth (quarterly log difference) } \\ \text { FRAGDP } & \text { France real GDP growth (quarterly log difference) } \\ \text { GBRGDP } & \text { UK real GDP growth (quarterly log difference) } \\ \text { DEUGDP } & \text { USA real growth in imports (quarterly log difference) } \\ \text { USAIMP } & \text { Japan real growth in imports (quarterly log difference) } \\ \text { JPNIMP } & \text { France real growth in imports (quarterly log difference) } \\ \text { FRAIMP } & \text { UK real growth in imports (quarterly log difference) } \\ \text { GBRIMP } & \text { Germany real growth in imports (quarterly log difference) } \\ \text { DEUIMP } & \end{array}$

Financial variables

USASTX

USA quarterly change in log stock prices

JPNSTX

Japan quarterly change in log stock prices

FRASTX

France quarterly change in log stock prices

GBRSTX

UK quarterly change in log stock prices

DEUSTX

Germany quarterly change in log stock prices

$\begin{array}{ll}\text { International commodities } & \begin{array}{l}\text { commodity price indices from the IMF } \\ \text { (quarterly log differences) } \\ \text { agmat }\end{array} \\ \text { bev } & \text { Agricultural materials } \\ \text { food } & \text { Beverages } \\ \text { indmat } & \text { Food } \\ \text { metal } & \text { Industrial materials } \\ \text { non-fuel } & \text { Metals } \\ \text { energy } & \text { Non fuels }\end{array}$


